\title{
NGNP Process Heat Applications: Hydrogen Production Accomplishments for FY 2010
}

The INL is a

U.S. Department of Energy National Laboratory

operated by

Battelle Energy Alliance

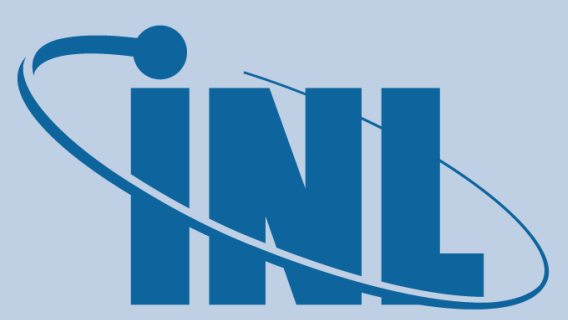

Idaho National Laboratory
January 2011

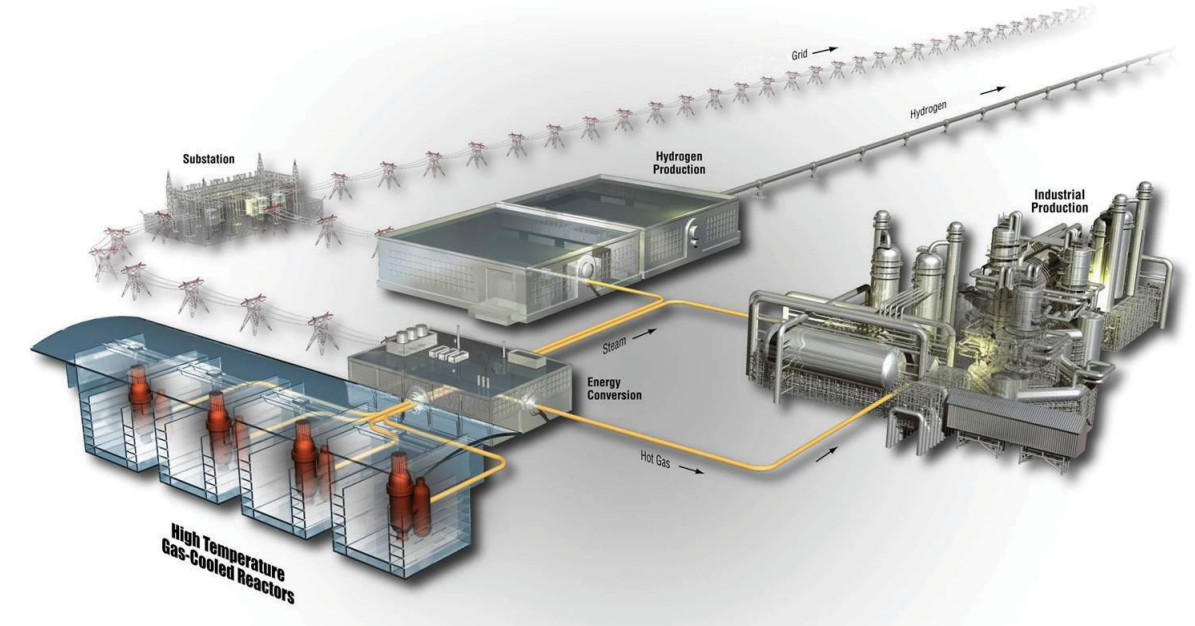




\section{DISCLAIMER}

This information was prepared as an account of work sponsored by an agency of the U.S. Government. Neither the U.S. Government nor any agency thereof, nor any of their employees, makes any warranty, expressed or implied, or assumes any legal liability or responsibility for the accuracy, completeness, or usefulness, of any information, apparatus, product, or process disclosed, or represents that its use would not infringe privately owned rights. References herein to any specific commercial product, process, or service by trade name, trade mark, manufacturer, or otherwise, does not necessarily constitute or imply its endorsement, recommendation, or favoring by the U.S. Government or any agency thereof. The views and opinions of authors expressed herein do not necessarily state or reflect those of the U.S. Government or any agency thereof. 


\section{NGNP Process Heat Applications: Hydrogen Production Accomplishments for FY 2010}

January 2011

Idaho National Laboratory

Next Generation Nuclear Plant Project

Idaho Falls, Idaho 83415

Prepared for the

U.S. Department of Energy

Office of Nuclear Energy

Under DOE Idaho Operations Office

Contract DE-AC07-05ID14517 
Next Generation Nuclear Plant Project

\section{NGNP Process Heat Applications: Hydrogen Production Accomplishments for FY 2010}

INL/EXT-11-20781

January 2011

Prepared By:

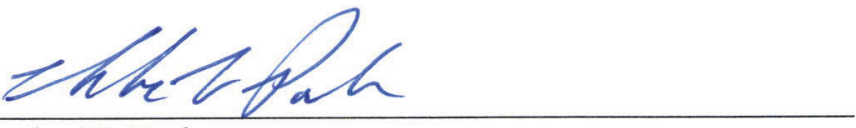

Charles V. Park

NGNP Heat Transfer Systems Engineer

25 IANUARY 2011

Date

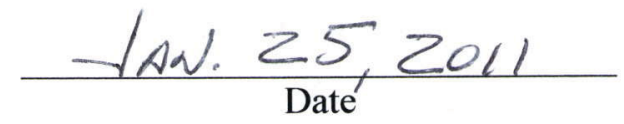

Approved by:

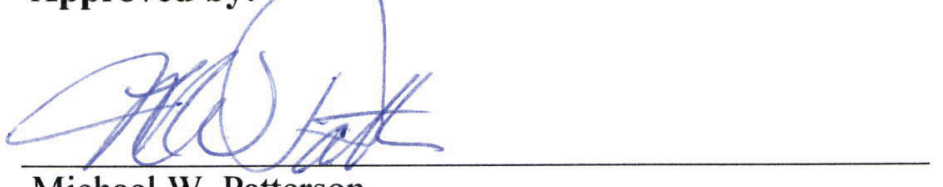

Michael W. Patterson

NGNP Process Heat Applications Project Manager

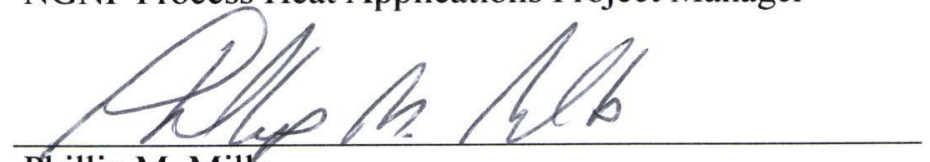

Phillip M. Mills

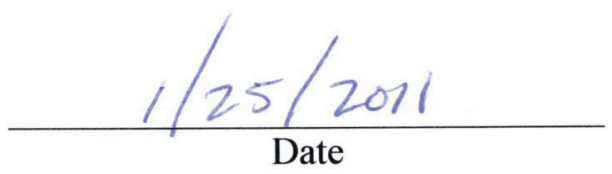

Engineering Director (acting)

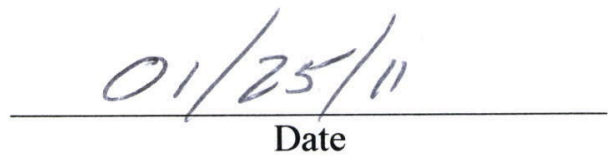




\section{SUMMARY}

This report summarizes FY 2010 accomplishments of the Next Generation Nuclear Plant (NGNP) Engineering Process Heat Applications group in support of hydrogen production technology development. This organization is responsible for the systems needed to transfer high temperature heat from a high temperature gas-cooled reactor, being developed by the NGNP Project at Idaho National Laboratory (INL), to electric power generation and potential industrial applications, including hydrogen production. Significant FY 2010 accomplishments related to hydrogen production include:

- Enhancements in INL testing capability:

- Fabrication and assembly of the Mixed Streams Test Rig, which is capable of testing materials at temperatures of $1000^{\circ} \mathrm{C}$ and pressures of 1,000 psig using a variety of gas compositions (helium, steam, oxygen, nitorgen, air, etc.). This equipment will be operated in FY 2011.

- Design and procurement of the Small Pressurized Component Test Rig, which is capable of testing high temperature and pressure components at temperatures up to $900^{\circ} \mathrm{C}$ and pressures up to $1,300 \mathrm{psig}$, and testing specimen sizes up to 8 inches and 150 pounds. This will be assembled and made ready for startup in FY 2011.

- Successful material testing:

- Diffusion bonding of Alloy $800 \mathrm{H}$, which can be used for high temperature applications, was demonstrated at INL. Diffusion bonding of Alloy $800 \mathrm{H}$ at laboratory scale was shown to maintain greater than $90 \%$ of its original tensile strength.

- Breakthrough materials and process performance modeling:

- State of the art thermodynamic, diffusion, and plasticity modeling was performed using Thermocalc $^{\odot}$ and Dictra ${ }^{\circ}$ to guide experimental design and evaluation of the alloy $800 \mathrm{H}$ diffusion bonds. These tools will significantly reduce the cost and schedule of testing high temperature materials.

- CFD was initiated to understand the complex heat transfer behavior within HTSE.

- Analyzed Tritium Permeation:

- The Tritium Permeation Analysis Code was is developed and tritium migration was measured in the High Temperature Test Reactor in Japan, This will help insure tritium does not adversely affect downstream processes, including hydrogen production.

- Insightful high temperature electrolysis cells (HTSE) integration with industrial applications:

- Studies were completed to evaluate the viability of High Temperature Steam Electrolysis cells to support various industrial applications, including: converting methanol from natural gas or coal to synthetic gasoline, producing synthetic diesel from natural gas or coal, producing ammonia derivatives from natural gas, providing steam assisted gravity drainage for oil sands recovery, and producing substitute natural gas from coal.

- Improved HTSE technical baseline:

- Completed a study of the cost and schedule required for subsequent scale-up of the HTSE process from pilot scale to the first-of-a-kind deployment with the NGNP.

- Completed a study of the reliability of expected HTSE components and developed an enhanced capability for RAM analysis. 


\section{CONTENTS}

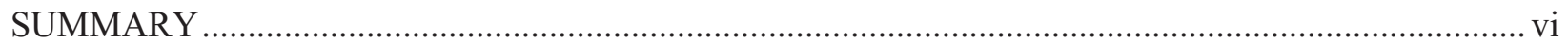

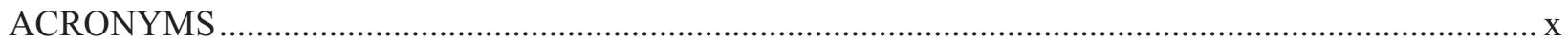

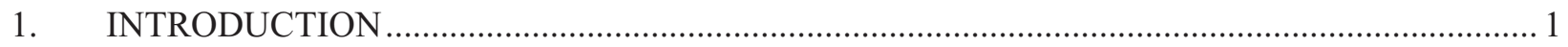

2. SIGNIFICANT HYDROGEN PRODUCTION RELATED ACCOMPLISHMENTS..................... 2

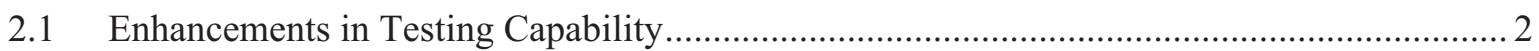

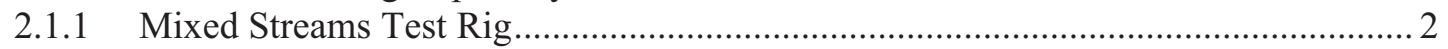

2.1.2 Small Pressure Cycling Test Rig ..................................................................... 3

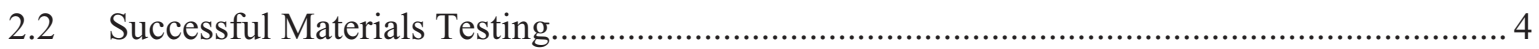

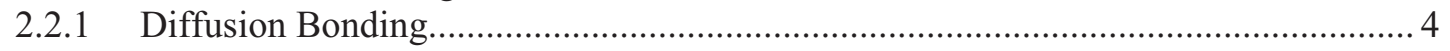

2.3 Breakthrough Materials and Process Performance Modeling ............................................ 6

2.3.1 Demonstrated Significant Correlation between Modeling and Experimental

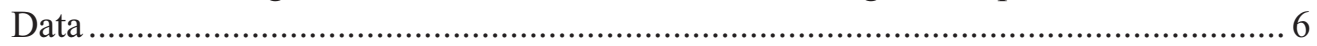

2.3.2 Computational Fluid Dynamic Modeling .......................................................... 8

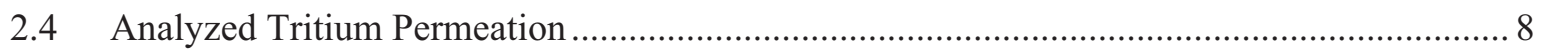

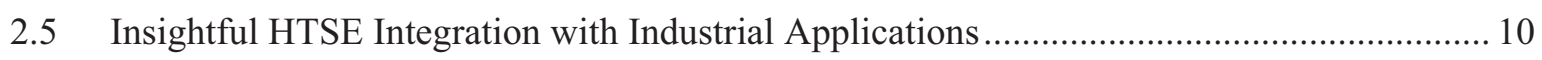

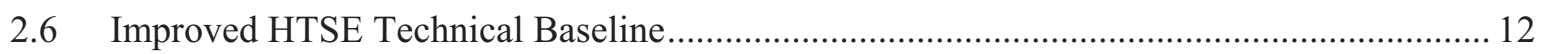

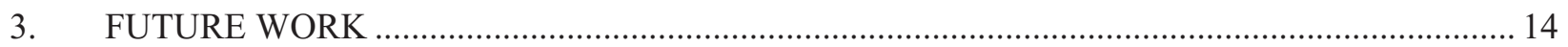

\section{FIGURES}

Figure 1. Hydrogen production integration within NGNP................................................................ 1

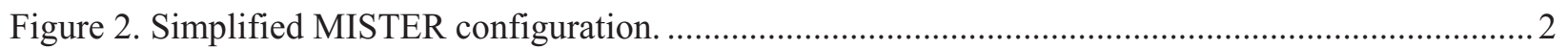

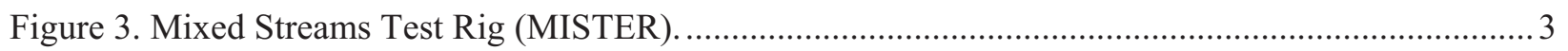

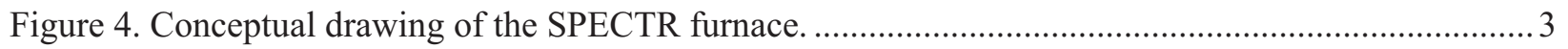

Figure 5. Diffusion bonded specimen in the Gleeble System............................................................ 4

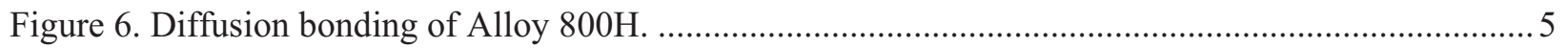

Figure 7. Tensile fractures of diffusion bonded $800 \mathrm{H}$ specimen. ....................................................... 5

Figure 8. Ultimate Tensile Strength of $800 \mathrm{H}$ diffusion bonds with varying surface preparations ............... 6

Figure 9. Comparison of modeled and experimental data for a diffusion weld of Alloy $800 \mathrm{H} \ldots \ldots \ldots \ldots \ldots \ldots \ldots . . . .7$

Figure 10. Computational mesh for internally manifolded SOEC ...................................................... 8

Figure 11. Frequency distribution of tritium concentrations in the hydrogen product without

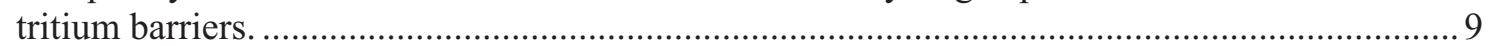

Figure 12. Cumulative Distribution Function of tritium concentrations in the hydrogen product. ............. 9

Figure 13. Flow sheet diagrams of conventional and HTGR-integrated hydrogen production processes......

Figure 14. Flow sheet diagrams of conventional and HTGR-integrated processes for a synthetic diesel production using coal. 
Figure 15. Life-cycle cost profile for HTSE demonstration. .

\section{TABLES}

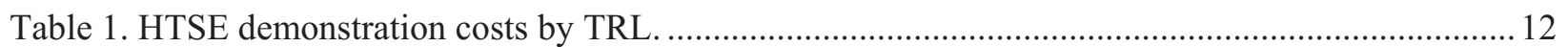




\section{ACRONYMS}

ASME American Society of Mechanical Engineers

BOP balance-of-plant

BPV Boiler \& Pressure Vessel Code

CFD computational fluid dynamics

DOE Department of Energy

FY fiscal year

HTSE high temperature steam electrolysis

HTGR high temperature gas-cooled reactor

HTTR High Temperature Test Reactor

INL Idaho National Laboratory

MISTER Mixed Streams Test Rig

NGNP Next Generation Nuclear Plant

RAM reliability, availability, and maintainability

R\&D research and development

SOEC solid oxide electrolysis cell

SPECTR Small Pressurized Component Test Rig

SS Stainless steel

TPAC tritium permeation analysis code

TRL Technology Readiness Level

VHTR very high temperature reactor 


\section{NGNP Process Heat Applications: Hydrogen Production Accomplishments for FY 2010}

\section{INTRODUCTION}

In response to a national strategic need identified in the National Energy Policy to promote reliance on safe, clean, economic nuclear energy and to establish a greenhouse-gas-free technology for the production of hydrogen, the Department of Energy (DOE) defined a mission need to develop new, advanced nuclear reactor and hydrogen production technology. The Next Generation Nuclear Plant (NGNP) represents an integration of high-temperature reactor technology with advanced capabilities for producing hydrogen, electricity, and process heat. Battelle Energy Alliance, LLC is advancing this technology at Idaho National Laboratory (INL) in conjunction with partners from industry and academia.

This report summarizes FY 2010 accomplishments supporting the development of hydrogen production related technology by the NGNP Engineering Process Heat Applications organization. Another significant effort, currently focused on improving cell performance, is underway within the Very High Temperature Reactor (VHTR) Technology Development Office to develop high temperature steam electrolysis (HTSE). The work of these two organizations is fully integrated. This report highlights the accomplishments of the NGNP Engineering Process Heat Applications organization, whereas other reports describe HTSE research and development (R\&D) accomplishments in FY 2010. Frequent integration meetings (usually biweekly) were held throughout the year to ensure that work was effectively executed and integrated. The simplified organizational relationship between Process Heat Applications and HTSE organizations is shown in Figure 1.

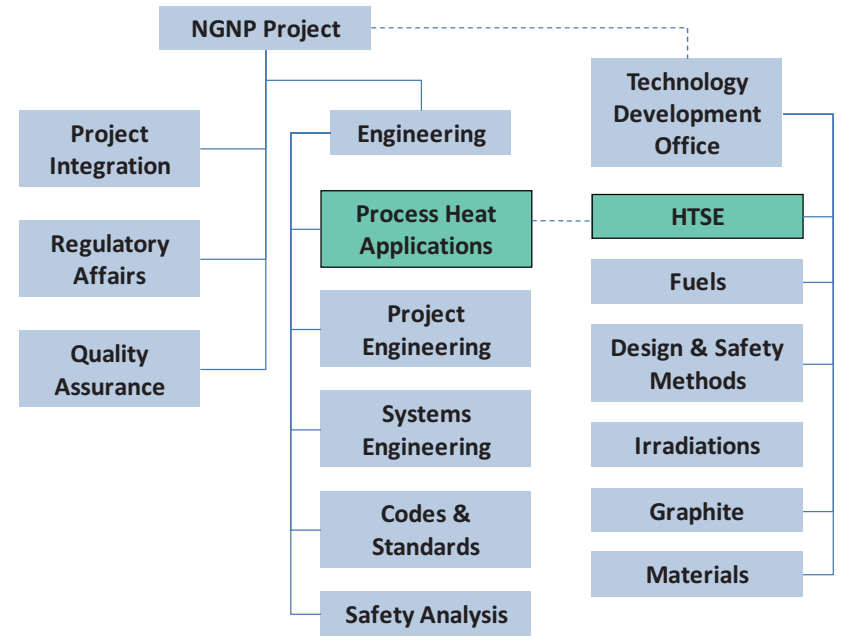

Process Heat Applications is responsible for

Figure 1. Hydrogen production integration within NGNP. the systems needed to transfer high temperature heat from the NGNP to potential industrial heat applications, including hydrogen production. These responsibilities include development of system components such as intermediate heat exchangers, steam generators, circulators, valves, seals, pressure relief systems, instruments and controls, and related materials, coatings, and contamination detectors and controls. Significant work was also accomplished in selecting, defining, and evaluating the potential of various industrial applications for use with NGNP, including hydrogen production.

FY 2010 accomplishments that advanced hydrogen production deployment are described in:

Section 2.1 Enhancements in testing capability

Section 2.2 Successful materials testing

Section 2.3 Breakthrough materials and process performance modeling

Section 2.4 Analyzed Tritium Permeation

Section 2.5 Insightful HTSE integration with industrial applications

Section 2.6 Improved HTSE technical baseline. 


\section{SIGNIFICANT HYDROGEN PRODUCTION RELATED ACCOMPLISHMENTS}

\subsection{Enhancements in Testing Capability}

\subsubsection{Mixed Streams Test Rig}

HTSE system components, such as gas manifolds and solid oxide electrolysis cell (SOEC) interconnects, are exposed to super-heated $\left(800\right.$ to $\left.900^{\circ} \mathrm{C}\right)$ hydrogen/steam and oxygen/air gas mixtures. Corrosion products from potential balance-of-plant (BOP) materials may contaminate SOEC components resulting in reduced performance. Thus, it is essential to choose materials with excellent corrosion performance under reducing and/or oxidizing environments at temperatures up to $900^{\circ} \mathrm{C}$ for very long lifetimes (up to 40,000 hours).

The Mixed Stream Test Rig (MISTER) was assembled in the Bonneville County Technology Center to test high temperature materials in various gas compositions. This equipment consists of two parallel gas streams that run separately through a 3 -foot-long horizontal tube furnace as conceptualized in Figure 2. This furnace is capable of temperatures up to $1000^{\circ} \mathrm{C}$ with the ability to vary gas compositions, including hydrogen, oxygen, steam, helium, and nitrogen, that can be expected within the HTSE process or heat transfer system. The system has a $\mathrm{H}_{2} / \mathrm{H}_{2} \mathrm{O}$ stream (referred to as the $\mathrm{H}_{2}$ stream) and $\mathrm{O}_{2} / \mathrm{N}_{2}$ stream (referred to as the $\mathrm{O}_{2}$ stream). Initial testing will utilize a median value of $66 \% \mathrm{H}_{2} / 33 \%$ steam for the HTSE cathode $\left(\mathrm{H}_{2}\right)$ stream and $50 \% \mathrm{O}_{2} / 50 \% \mathrm{~N}_{2}$ for the anode HTSE $\left(\mathrm{O}_{2}\right)$ stream. The specimen materials will be placed on $\mathrm{ZrO}_{2}$ boats and placed inside 1-inch-diameter Hastelloy 214 tubes. Initial testing in FY 2011 will validate operation of this test apparatus and develop some baseline data for selecting candidate BOP and SOEC materials.

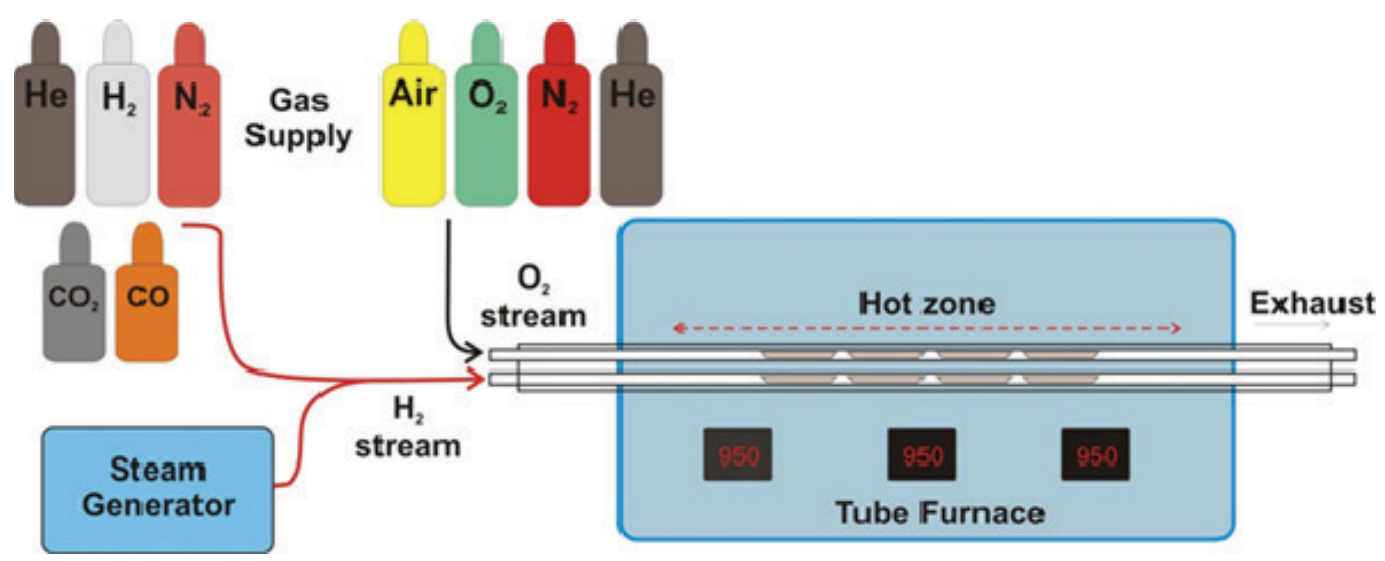

Figure 2. Simplified MISTER configuration.

A detailed description of the major systems of MISTER can be found in INL PLN-3502, "MixedGases Materials Test Plan," dated May 7, 2010. MISTER will be operated in FY 2011 to provide information for selecting high temperature materials for BOP and SOEC components. This test equipment can be configured for future testing up to $1,000 \mathrm{psig}$, testing materials with different gases on either side of a pressure boundary, temperature and pressure cycling, and materials under load.

Figure 3 shows a photo of MISTER layout with the experimental control monitors in front of the tube furnace. At the inlet to the furnace (between the furnace and the wall) is the rack that holds the mass flow controllers, the steam generator, humidifier, and other gas conditioning components. To the right of the photo (not shown) are the compressed cylinders for gas supply. 


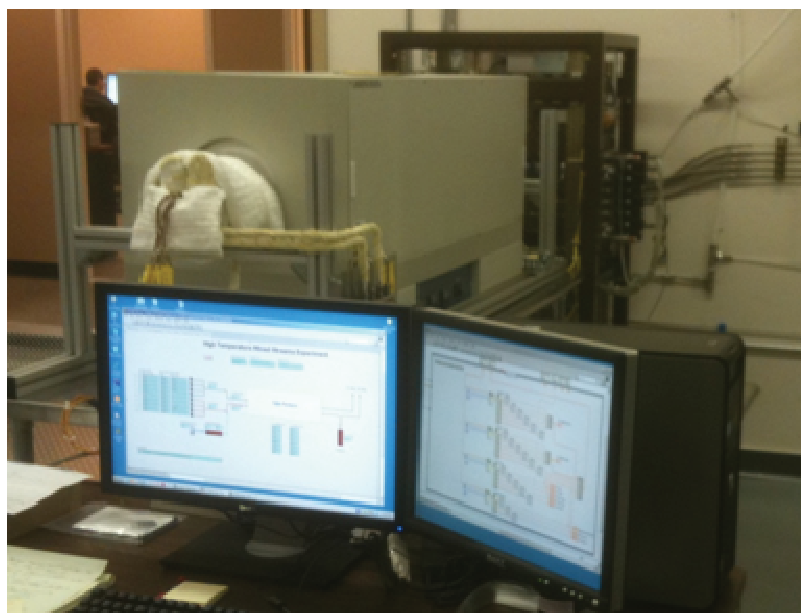

Figure 3. Mixed Streams Test Rig (MISTER).

\subsubsection{Small Pressure Cycling Test Rig}

INL initiated design and procurement of the Small Pressure Cycling Test Rig (SPECTR) to test pressurized components at temperatures up to $900^{\circ} \mathrm{C}$. Components for testing will be delivered and assembled in FY 2011. SPECTR is capable of testing small HTSE stacks (up to $150 \mathrm{lb}$ but with dimensions of less than 8 inches maximum) at pressures up to $1,300 \mathrm{psig}$. Initial testing planned for intermediate heat exchanger components consists of cyclic (fatigue) pressure testing or gas permeation testing and is configured as shown in Figure 4. The environment around the test article can be any inert gas and the pressure of the environmental gas can be as high as 150 psig.

\section{Small Pressure Cycling Test Rig (SPECTR) Concept}

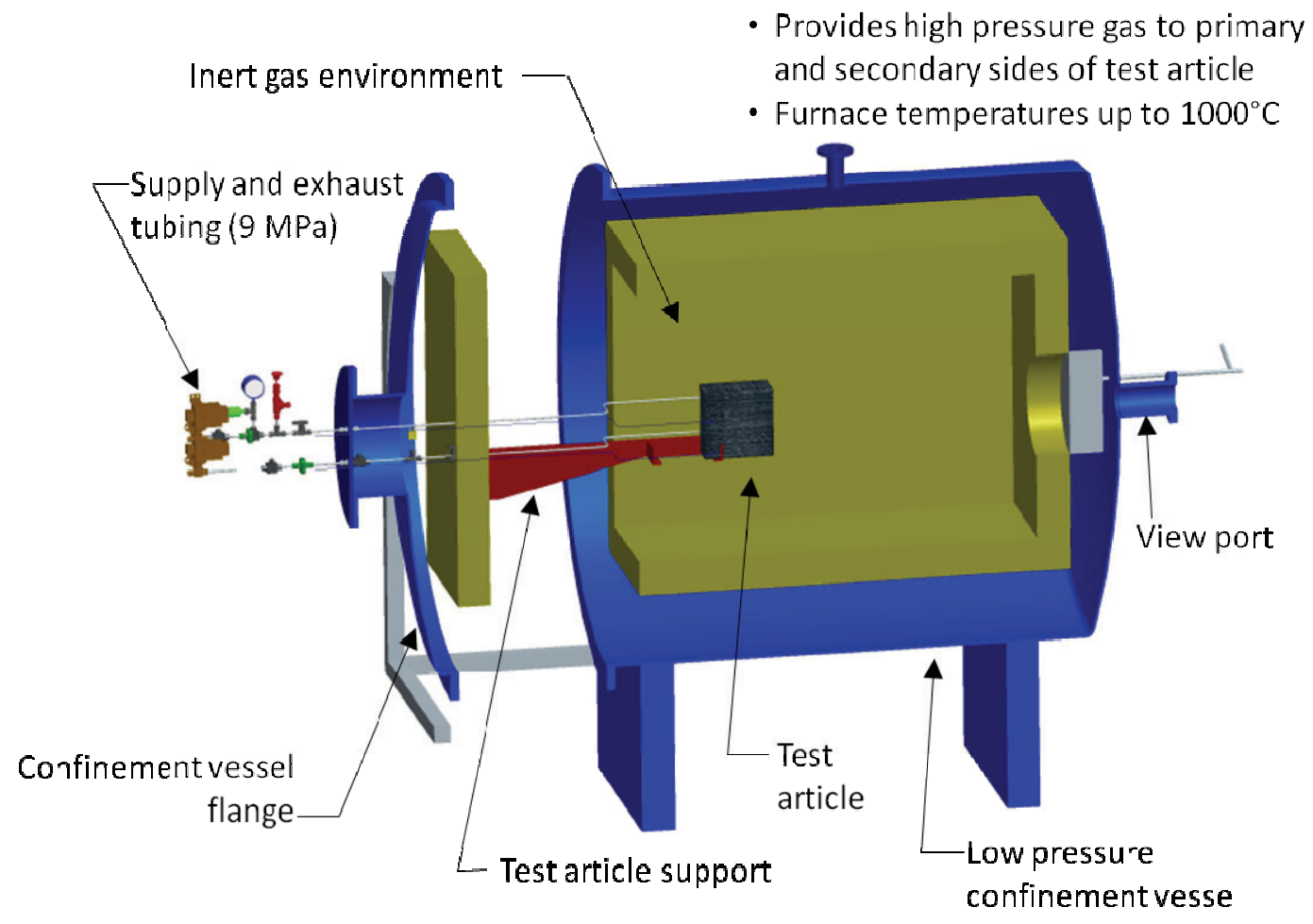

Figure 4. Conceptual drawing of the SPECTR furnace.

The SPECTR furnace is currently being manufactured and is expected to be operational in June 2011. The gas supply system may be modified in the future to provide contaminants at concentrations of parts per million up to $0.1 \%$ by volume. This pressurized test equipment will be instrumental in providing data to establish American Society of Mechanical Engineers (ASME) Boiler \& Pressure Vessel Code (BPV) Section III, Division 5, Code Case justification for high temperature materials. The next significant hurdle for HTSE technology is to demonstrate SOEC operation at pressure. SPECTR can be used to accomplish this significant achievement. 


\subsection{Successful Materials Testing}

\subsubsection{Diffusion Bonding}

Diffusion bonding is a solid-state welding process by which two metals can be bonded together. Diffusion involves the migration of atoms across the joint because of concentration gradients. The two materials are pressed together at an elevated temperature, usually between 50 and $70 \%$ of the melting point. Pressure is used to reduce voids that may occur due to different surface topographies.

The NGNP Project is currently investigating the use of diffusion bonding for the fabrication of flat plate, microchannel heat exchangers to meet the requirements of ASME BPV Section III, Division 5. An example of this type of design is a printed-circuit heat exchanger, which consists of metal plates that have millimeter-scale semicircular fluid-flow channels photo-chemically milled on the surface using a process analogous to that used for the manufacture of electronic printed circuit boards. The plates are then stacked and diffusion-bonded together to fabricate a heat exchanger core. Other NGNP components that may use diffusion bonding include HTSE SOEC interconnects, high temperature steam generators, and recuperators.

A scoping study was initiated to evaluate diffusion bonding process parameters and the resultant mechanical properties of the diffusion bonded joint. Engineering evaluations include initial application to ASME to qualify the process for acceptance in accordance with the requirements of ASME BPV Section III. Initial diffusion bonded specimens of alloy $800 \mathrm{H}$ were made using a Gleeble System, a generalpurpose servohydraulic thermomechanical testing device as shown in Figure 5. The development work plan is summarized in INL PLN-3565, "Scoping Investigation of Diffusion Bonding for NGNP Process Heat Applications," dated August 7, 2010.

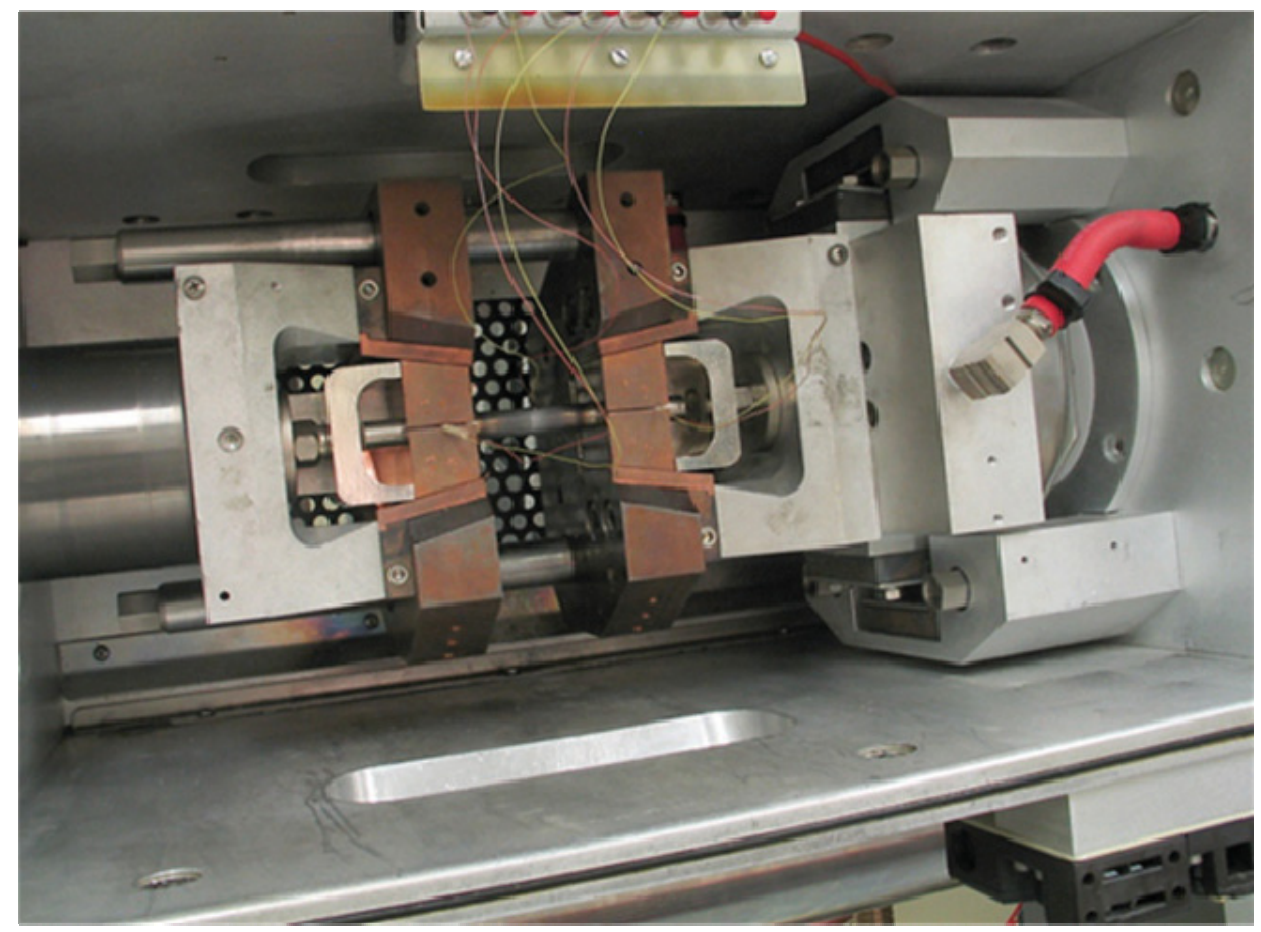

Figure 5. Diffusion bonded specimen in the Gleeble System. 
The Gleeble equipment provides a vacuum or controlled atmosphere chamber required to control the surface oxidation of candidate heat exchanger alloys such as Alloy $800 \mathrm{H}$. Heating of a specimen held in watercooled grips is provided by Joule (resistance) heating, which is feedback-controlled by an attached thermocouple. An image of a specimen during the diffusion bonding process in the Gleeble System is shown in Figure 6. The strength of the Gleeble System is in its ability to reproduce the thermal and mechanical effects of the diffusion bonding process. The test material chosen for scoping studies is a one-half-inch-diameter bar of Alloy $800 \mathrm{H}$ exposed to the same thermal and mechanical profile that it would see in the full-scale diffusion-bonding process. Data developed in these tests can be transferred

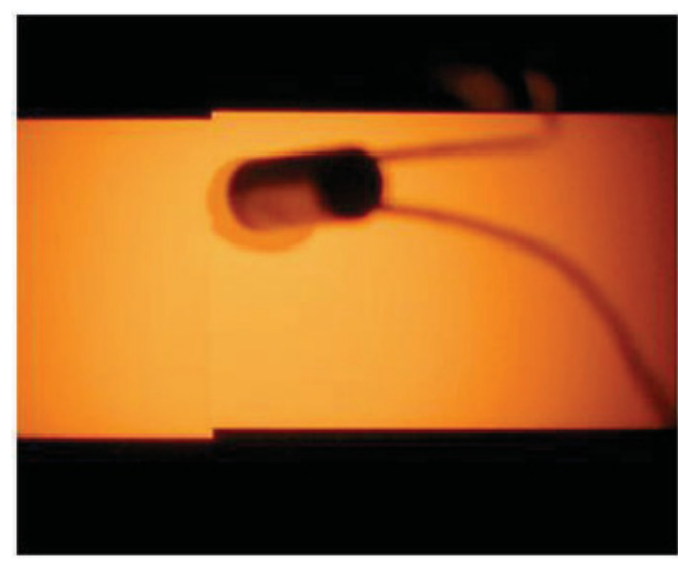

Figure 6. Diffusion bonding of Alloy $800 \mathrm{H}$. from the laboratory to the full-size production process.

Diffusion bonding tests achieved impressive results. The specimen at the top of Figure 7 shows the tensile test fracture of "as received" $800 \mathrm{H}$ bar stock, which exhibits ductile fracture behavior. Ductile fracture is also observed in the next two specimens (Y00127 and Y00223), where the results of diffusion bonding with nickel-plated faying surfaces $(1 \mu \mathrm{m}$ on each surface) and insertion of a nickel foil filler material $(15 \mu \mathrm{m})$ is illustrated. The bottom specimen was bonded after surface cleaning, but had no nickel plating or nickel filler layer. This sample (Y00128) exhibits limited ductility as compared to the other test specimens.

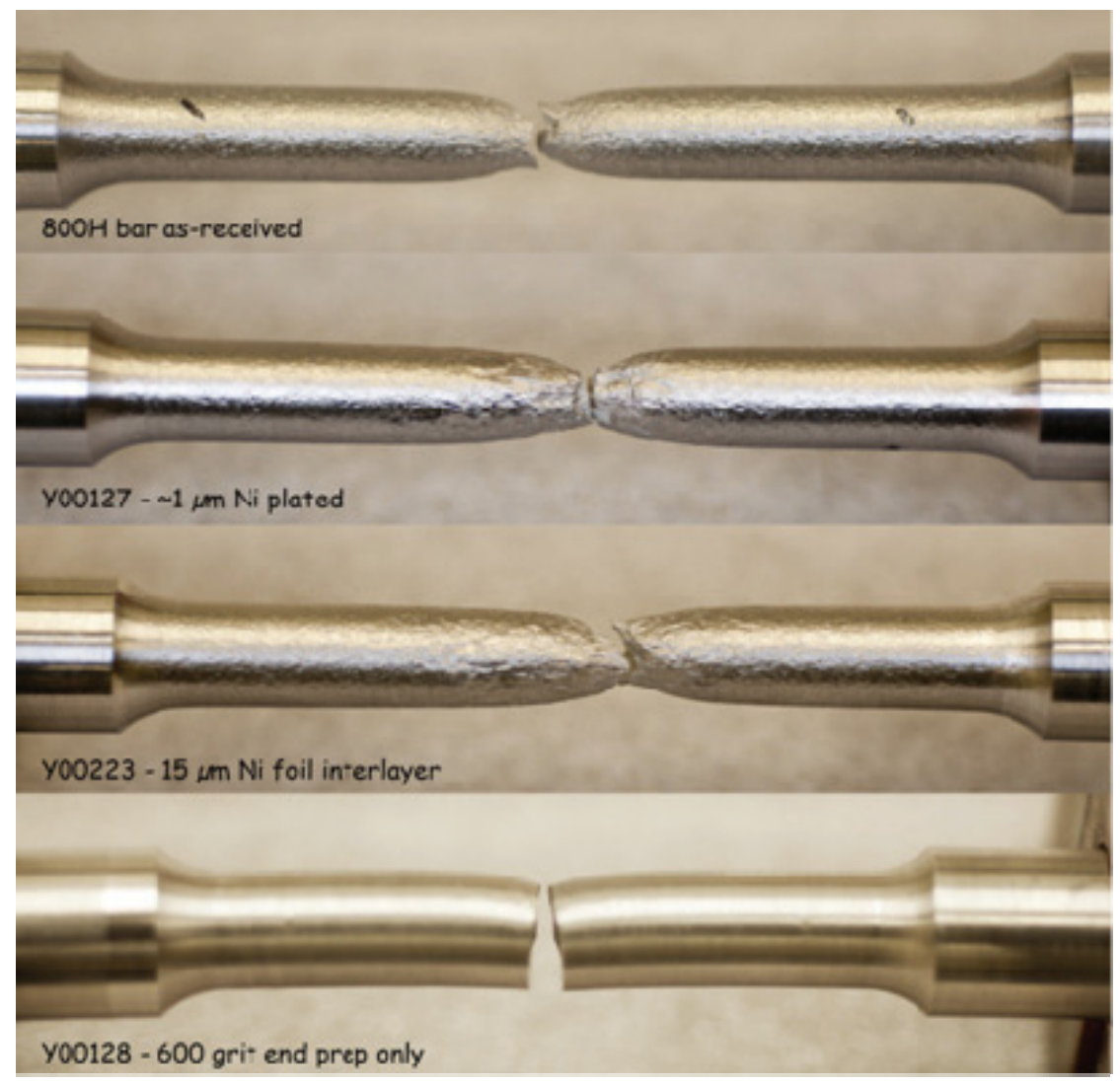

Figure 7. Tensile fractures of diffusion bonded $800 \mathrm{H}$ specimen. 
Figure 8 Shows that all of the diffusion bonds that included nickel foil or plating at the interface maintained over $90 \%$ of the initial ultimate tensile strength.

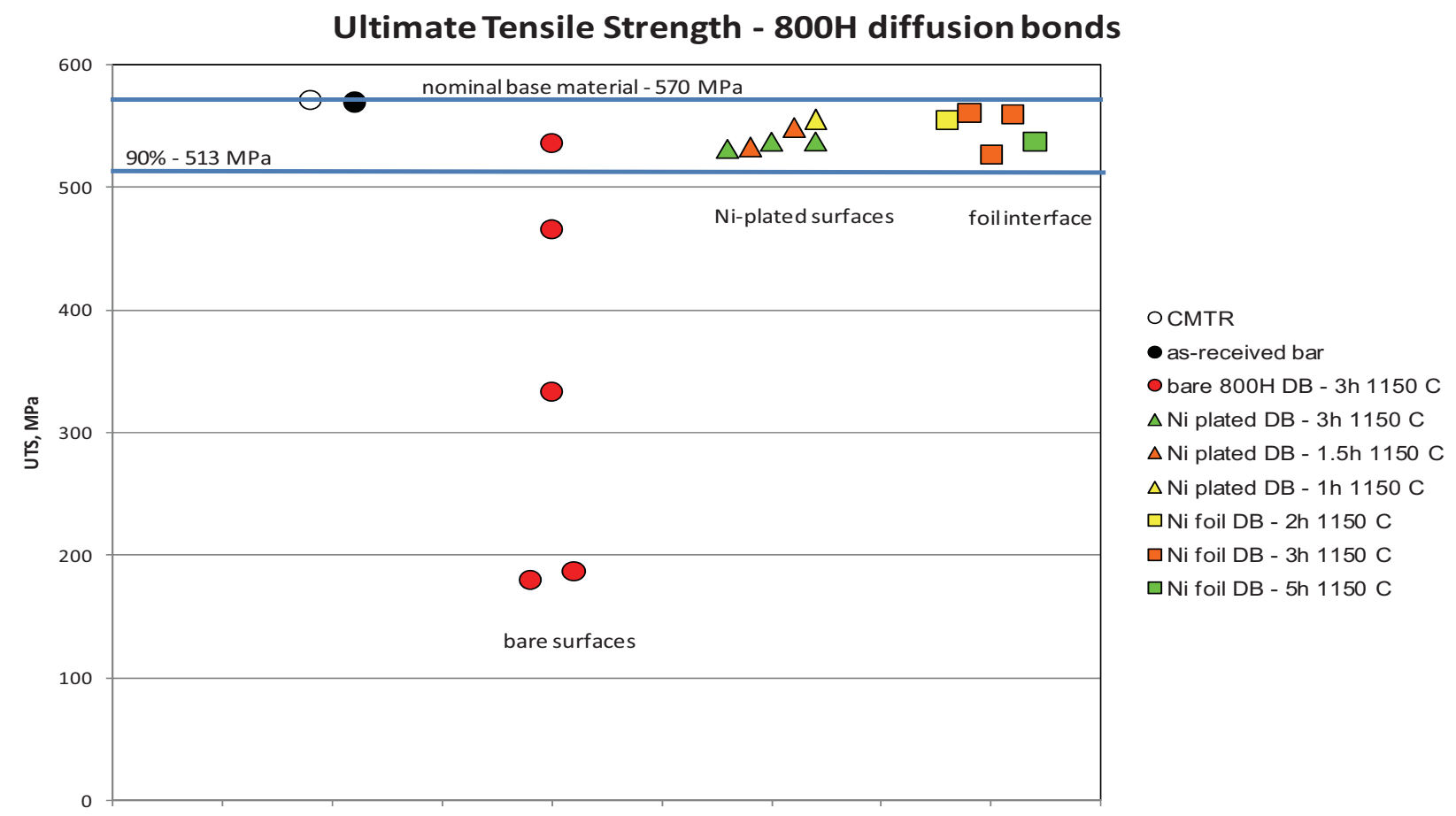

Figure 8. Ultimate Tensile Strength of $800 \mathrm{H}$ diffusion bonds with varying surface preparations

Focused materials testing was aided by the use of powerful new computational modeling tools (Thermo-Calc ${ }^{\mathcal{O}}$ and the Dictra ${ }^{\mathcal{O}}$ ), in order to optimize the parameters for diffusion welding of Alloy $800 \mathrm{H}$. These sophisticated tools are described in Section 2.3.

\subsection{Breakthrough Materials and Process Performance Modeling}

\subsubsection{Demonstrated Significant Correlation between Modeling and Experimental Data}

Dictra $^{\circledR}$ is a versatile modeling tool that allows analysis of practically all of the diffusion controlled phenomena in metallurgical systems. Work was limited to the construction of elemental concentration profiles for all of the chemical elements in Alloy $800 \mathrm{H}$ in contact with pure nickel. Both modeling and physical testing were performed to validate model usefulness and accuracy. The diffusion welded joint consisted of the faying (bonding) surfaces of Alloy $800 \mathrm{H}$ with a $15-\mu \mathrm{m}$-thick pure nickel filler metal layer.

A Dictra ${ }^{\circledR}$ generated concentration profile is superimposed on a sample profile measured with the energy-dispersive spectrometry in a scanning electron microscope as illustrated in Figure 9. It can be seen that in the case of such elements as chromium, iron, and nickel there is strong agreement between the results of calculations and experimentally measured concentration profiles using energy-dispersive spectrometry. 
Comparison of Model and Experimental Data

SEM/EDS analysis of Diffusion Bonded Specimen Y00804A: $15 \mu \mathrm{m} \mathrm{Ni}$ interlayer, $3600 \mathrm{~s}, 1150^{\circ} \mathrm{C}, 5 \mathrm{MPa}$

Thermocalc/DICTRA model at $3600 \mathrm{~s}$

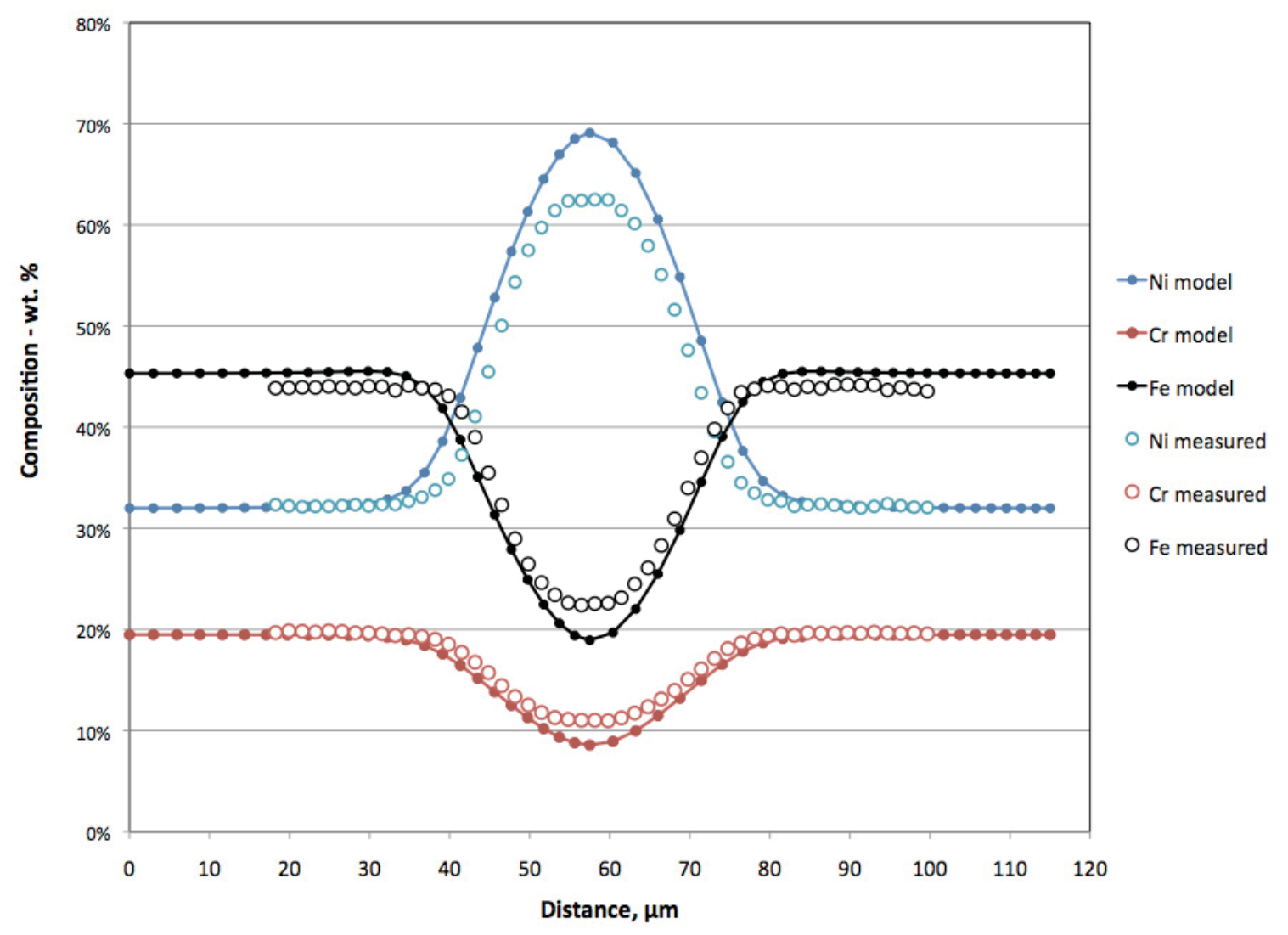

Figure 9. Comparison of modeled and experimental data for a diffusion weld of Alloy $800 \mathrm{H}$.

This computational modeling and measurement approach will be used to develop diffusion welding parameters for other materials of interest, such as Alloy 617, resulting in reduced future experimental costs because only the most promising materials and process conditions will be tested. The software and modeling staff costs were shared between NGNP Engineering and HTSE R\&D in order to benefit both programs.

INL personnel also performed atomic-scale thermodynamic and diffusion modeling of SOECs. The thermodynamic properties, microstructure, and phase equilibrium of 441 stainless steel (SS) interconnects within the SOECs were evaluated at $800^{\circ} \mathrm{C}$. The principal problem with this material is that the chromium from $441 \mathrm{SS}$ poisons the electrolyte in the SOEC and reduces the operating life of the cell as a result of decreasing efficiency. The surface of $441 \mathrm{SS}$ also becomes oxidized, resulting in the formation of porous chromium- and iron-bearing oxide layers. The next step will be to use the Dictra ${ }^{\circledR}$ diffusion modeling tool to determine appropriate coatings that may mitigate $441 \mathrm{SS}$ degradation. Computations are planned for diffusion coupled $441 \mathrm{SS} /$ nickel and $441 \mathrm{SS} /$ copper to develop practical recommendations on the thickness of the proposed coating to efficiently block oxidation and chromium poisoning for up to 20,000 hours, which is the threshold operating life at which the HTSE concept becomes economically feasible. 


\subsubsection{Computational Fluid Dynamic Modeling}

This work developed a 3-D computational fluid dynamic (CFD) model of an internally manifolded SOEC for use in the HTSE process. When operational, this CFD model will predict the heat transfer, flow distribution, and species concentrations within HTSE cells. A detailed analysis of the complex electrochemical and mass transport phenomena occurring in the cell is necessary to detect nonuniformities that cannot be understood using a more simplified approach.

Equations for mass, momentum, energy, and species conservation and transport are solved using the commercial CFD code ANSYS Fluent 12.1. The electrochemical reactions, loss mechanisms, and electric field through the cell are computed via an add-on fuel cell module. The main difference between the latest fuel cell module and that previously developed by the DOE National Energy Technology Laboratory under the Solid State Energy Conversion Alliance program is that the computations take place internally in the ANSYS Fluent software, rather than being solved via user-defined functions contained in external routines.

A test case was set up and successfully executed in FY 2010. The configuration and operating conditions of the cell/stack to be modeled were identified. The numerical model is based on a typical internally manifolded 6-inch-square planar SOEC. An initial computational mesh was created and boundary conditions and solver parameters for a single SOEC were specified. The INL analyst worked with the vendor to incorporate model parameters, electrochemistry specifications, electrolyte and electrode details, and electric field settings for their SOEC design. The project created an initial CFD model of an electrode-supported, internally-manifolded SOEC. The computational mesh for this design is shown in Figure 10.

\subsection{Analyzed Tritium Permeation}

Tritium permeation is an important issue in the development of the NGNP because tritium is easily permeated through high temperature metallic materials. Tritium permeation in NGNP-integrated systems was investigated using the tritium permeation analysis code (TPAC) developed by INL. The INL TPAC is a numerical tool based on the mass balance equations of tritium-containing species and hydrogen (tritium, hydrogen, and tritiated water) coupled with a variety of tritium source, sink, and permeation models. In the TPAC, ternary fission and thermal neutron capture reactions with ${ }^{6} \mathrm{Li},{ }^{7} \mathrm{Li}^{10} \mathrm{~B}$, and ${ }^{3} \mathrm{He}$ were taken into consideration as tritium sources. Purification and leakage models were implemented as main tritium sinks. Permeation of tritium and hydrogen through pipes, vessels, and heat exchangers was considered as main tritium transport paths. In addition, electrolyzer and isotope exchange models were developed for analyzing hydrogen production systems including HTSE. The report of this analysis is in draft form and will be issued in FY 2011 as Scoping Analysis on Tritium Permeation to VHTR Integrated Industrial Application Systems (INL/EXT-1019607).

This study includes a Monte Carlo-based sensitivity analysis for three nuclear-assisted process applications: VHTR/HTSE $\left(900^{\circ} \mathrm{C}\right)$, high temperature gas-cooled reactor $(\mathrm{HTGR}) / \mathrm{HTSE}\left(750^{\circ} \mathrm{C}\right)$, HTGR/methanol to gasoline and HTGR/improved methanol to gasoline. Discussions on the efficient methods to reduce model uncertainties and mitigate tritium permeations in the system are also included. 
As an example of the information provided by the scoping analysis, Figures 11 and 12 show the probability and cumulative distributions, respectively, of the tritium concentrations in the product hydrogen for a system designed to have the reactor outlet temperature of $750^{\circ} \mathrm{C}$. According to the results, the tritium concentration in the product hydrogen is widely distributed for the selected input parameters. About $30 \%$ of the cases are within the effluent limit $\left(3.7 \times 10^{-3}\right.$ $\mathrm{Bq} / \mathrm{cm}^{3}[\mathrm{STP}]$ set by NRC), and $70 \%$ exceed the effluent limit. The maximum tritium concentration in the system reached up to 0.1 $\mathrm{Bq} / \mathrm{cm}^{3}[\mathrm{STP}]$, which is two orders of magnitude higher than the effluent limit. It indicates that novel tritium permeation barrier methods or purification and removal systems should be implemented into the actual heat exchanger design and fabrication to achieve sufficiently low tritium concentration. Input included data from Peach Bottom experience (an HTGR operating from 1966 to 1974 near Harrisburg Pennsylvania) and an INL experimental laboratory.

Preliminary conclusions drawn from this study are that tritium produced from ternary fission presents the largest source of uncertainty in the model. Further investigation of that source term and the components affecting it - tritium permeation through the TRISO particle and tritium hold-up in graphite - offer the best opportunity to reduce model uncertainty. Other results from the analysis include the observations that

(1) purification systems located in the primary circuit will have a greater effect on tritium concentrations than purification systems located closer to the process application, and (2) increases in heat exchanger thickness (or by inference, heat exchanger coatings) will have greater impact closer to the process application.

TPAC is being validated with data from the High Temperature Test Reactor (HTTR) at Oarai, Japan that was restarted in January 2010. Temperature and power were increased in accordance with the test specification and tritium samples were collected before and during the rise to power. Samples at full power and temperature (roughly $30 \mathrm{MWth}$ and $950^{\circ} \mathrm{C}$ ) continued through March 2010. NGNP Engineering and QA personnel traveled to the HTTR in Oarai, Japan, during the week of February 22, 2010 , to perform an onsite evaluation of tritium sampling. 


\subsection{Insightful HTSE Integration with Industrial Applications}

NGNP Engineering completed a number of analyses to determine the technical feasibility of integrating HTGR technology into conventional industrial processes and to determine its potential environmental and economic benefits. To develop a credible baseline for comparing nuclear-integrated and conventional processes, a conservative approach was used for the assumptions and calculations. The studies included:

- Electric power generation

- Hydrogen production using HTSE

- Methanol to synthetic gasoline production from natural gas or coal

- Synthetic diesel production from natural gas or coal

- Ammonia derivatives production from natural gas or coal

- Steam assisted gravity drainage for oil sands recovery

- Substitute natural gas production from coal.

These engineering analyses show that HTGR-integrated processes would sharply reduce carbon dioxide and other greenhouse gas emissions, primarily by replacing the heat derived from natural gas and coal with high-temperature process heat from an HTGR, but also by incorporating more of the carbon from natural gas or coal into the product. These analyses are significant because they demonstrate the environmental and potential economic benefits of using HTGR technology.

For example, an HTGR-integrated process model was developed based on the hydrogen production capacity of a typical conventional steam reformer (approximately 700 tons/day hydrogen). The model assumed a Rankine power cycle efficiency of $40 \%$ and the results were used to develop HTGR-integrated alternatives for processes that require hydrogen (via HTSE), such as synthetic gasoline and diesel production from coal. As shown in Figure 13, HTGR-generated hydrogen avoids the production of nearly 3,400 tons/day of carbon dioxide compared to a conventional steam reformer.

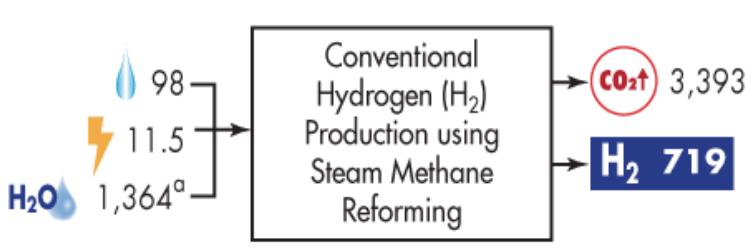

Model Basis:

$\mathbf{H}_{2}$ Hydrogen $\left(\mathrm{H}_{2}\right)$ (tons/day)

(1) Natural Gas (millions of cubic feet/day)

$\mathrm{H}_{2} \mathrm{O}$ Water (gallons/minute)

4 Electricity $\left(\mathrm{MW}_{\mathrm{e}}\right)$

M 600-MW th $_{\text {HTGR }}$

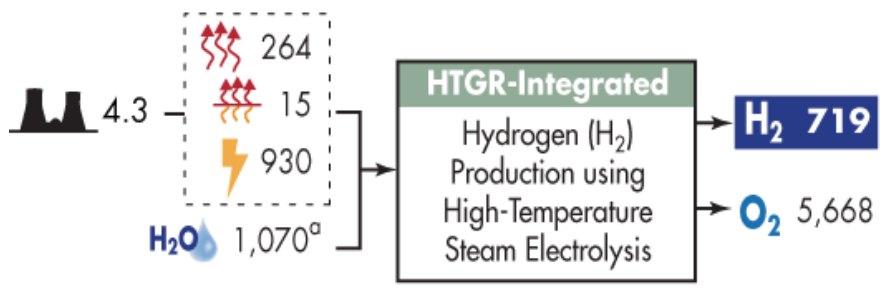

$5 \% 5$ Process Heat $\left(M W_{\text {th }}\right)$

製 Topping Heat $\left(M W_{\text {th }}\right)$

(60.7) Carbon Dioxide Emitted (tons/day)

$\mathbf{O}_{2}$ Oxygen $\left(\mathrm{O}_{2}\right)$ (tons/day)

a. Amount needed as feedstock for hydrogen production.

Figure 13. Flow sheet diagrams of conventional and HTGR-integrated hydrogen production processes.

The economic analyses were based on a simplified business model that represents a single entity that owns and operates both the HTGR plant and the conventional industrial process plants. A more likely business model would be an HTGR plant owned and operated by a separate entity consisting of multiple modules to ensure a stable and reliable supply of process heat and/or electricity for multiple end users. 
However, uncertainties associated with some of the cost elements and data, as well as the complexity of modeling multiple products for multiple users, favored the development of a simplified business model to provide first-order approximation of the relative costs and benefits. The results of the economic analysis establish a baseline and may be understood as relative values as opposed to absolute values.

Economic analysis results show that, in the absence of a carbon tax or significantly higher natural gas prices than current (\$6.50/MSCF), HTGR-integrated HTSE would be less economically viable than a conventional steam methane reforming process. This is primarily because of the larger initial capital investment required for the HTGR compared to that for a conventional process. The economic viability of the HTGR-integrated HTSE process would improve with higher HTGR outlet temperatures and increased HTSE technical maturity.

This analysis indicated that an increase in power cycle thermal efficiency (beyond the assumed 40\%) would be accompanied by an increase in hydrogen production. If the HTGR outlet temperature is increased to $900^{\circ} \mathrm{C}$, the power cycle thermal efficiency would increase to $53 \%$, the need for topping heat would be eliminated, and hydrogen production would increase by $35 \%$.

Another example of beneficial use involves converting coal to synthetic diesel using HTSE to supply hydrogen to the process. The analysis of the conventional coal-based case showed few opportunities for heat integration because the production process generates more than sufficient heat to provide for heat requirements. However, the analysis showed an opportunity to use HTSE, which could provide hydrogen and oxygen while reducing coal requirements and subsequent GHG emissions. In the conventional process, only one-third of the carbon in the coal ends up in the final product as compared to over $98 \%$ in the HTSE-integrated case.

The HTSE-integrated process would produce a secondary product of 6,414 tons/day oxygen, which could be sold or redirected to another process. However, the revenue from the sale of oxygen was not included in this economic evaluation because of the lack of demand for large volumes of oxygen. This process would also generate less carbon dioxide emissions than the conventional process, even if the conventional process includes carbon capture and sequestration. Figure 14 shows flow sheet diagrams of the conventional process and this HTSE-integrated alternative.

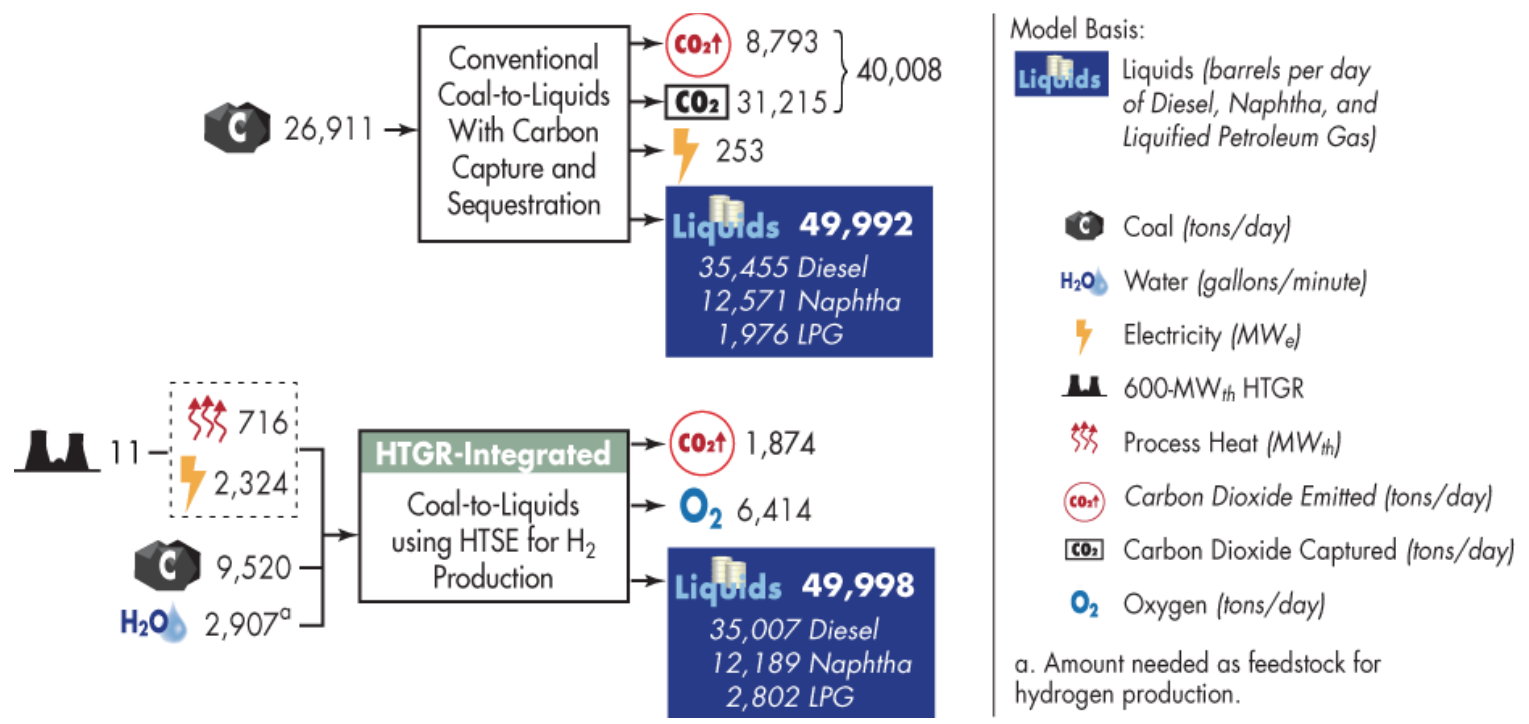

Figure 14. Flow sheet diagrams of conventional and HTGR-integrated processes for a synthetic diesel production using coal. 
These analyses provide a credible baseline for evaluating the technical, environmental, and economic viability of various industrial processes. The results are issued in Nuclear-Integrated Hydrogen Production Analysis, (TEV-693) Revision 1, Dated May 15, 2010; and Nuclear-Integrated Coal and Gas to Liquids Production Analysis, (TEV-672) Revision 1, Dated May 15, 2010. They can be updated and modified as needed for different economic conditions and technology advances.

Two significant conclusions were reached relative to HTGR-integrated processes:

- The evaluated HTGR-integrated industrial processes, including electricity generation and hydrogen production, have a significantly lower carbon footprint than conventional processes.

- Some of the evaluated HTGR-integrated industrial processes appear to have economic viability similar to conventional processes, even without a carbon tax or a substantial increase in natural gas prices.

\subsection{Improved HTSE Technical Baseline}

An understanding of the cost and schedule required to deploy HTSE was advanced by two key studies. Much of this work is captured in INL TEV-919, "RAM Analysis and Life-Cycle Cost Estimate of High-Temperature Steam Electrolysis (HTSE),” dated August 31, 2010.

The first study was a reliability, availability, and maintainability (RAM) analysis to identify critical areas for technology development based on available information regarding expected HTSE component performance. The HTSE process baseline flow sheet (sized for commercial scale) was used as a basis. The NGNP project also established a process and capability to perform future RAM analyses. The analysis identified which components had the greatest impact on HTSE process availability, indicating that the HTSE process could achieve over 90\% availability at TRL-10, which is the NGNP target availability at the $\mathrm{n}^{\text {th }}$-of-a-kind commercial demonstration.

The second study developed a series of life-cycle cost estimates for the various scale-ups required to demonstrate HTSE technology. These are considered Class 5 estimates in accordance with the Association for Advancement of Cost Engineering International. This means that the estimates are uncertain and should only be used for concept screening or feasibility evaluations. A Class 5 estimate is based on a level of project definition (expressed as a percentage) that is less than $2 \%$. Therefore, these cost estimates provide only possible categories, amounts, and timing of funding needed to demonstrate the HTSE process through engineering-scale demonstration. They present a preliminary basis for lifecycle planning, and will be updated as the HTSE technology advances through progressive Technology Readiness Levels (TRLs). At this level of program maturity, the cost estimate varies by minus $50 \%$ to plus $100 \%$. The programmatic cost to achieve TRL-6 and TRL-7 is about $\$ 200 \mathrm{M}$, as shown in Table 1 . The cost to achieve TRL-8 and TRL-9 were not estimated in this report. The cost to achieve TRL-5 (about $\$ 5 \mathrm{M}$ per year) was also not included in these estimates.

Table 1. HTSE demonstration costs by TRL.

\begin{tabular}{|r|c|c|c|}
\hline \multicolumn{1}{|c|}{ Scale (TRL) } & $\begin{array}{c}\text { R\&D \& Operations } \\
\text { (\$M) }\end{array}$ & $\begin{array}{c}\text { Engineering/Capital } \\
\text { (\$M) }\end{array}$ & $\begin{array}{c}\text { Total } \\
\text { (\$M) }\end{array}$ \\
\hline Pilot scale (6) & 23 & 40 & 63 \\
\hline Engineering scale (7) & 25 & 115 & 140 \\
\hline Total & 48 & 155 & 203 \\
\hline
\end{tabular}

Both studies were useful in identifying near- and long-term efforts necessary for successful HTSE process deployment. The progressive size and capability of technology demonstration scale-ups was refined, and helps to plan the near- and long-term cost and schedule of deployment. The life-cycle 
funding profile, with high-level allocations, was identified as the program transitions from experiment scale R\&D to engineering scale demonstration and is summarized in Figure 15.

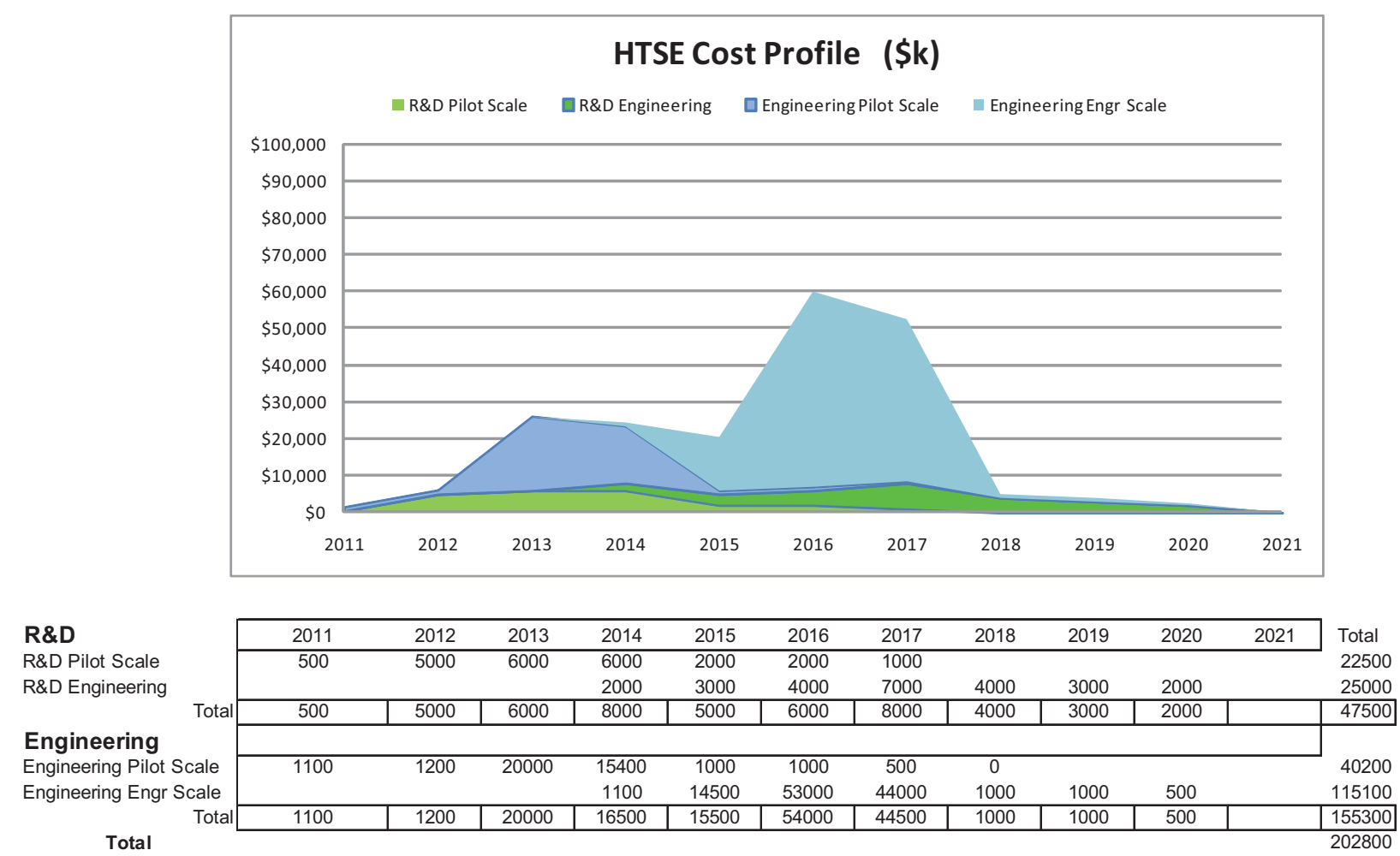

Figure 15. Life-cycle cost profile for HTSE demonstration.

HTSE risks and requirements as a part of the technical baseline were also updated for consistency with the studies completed in FY 2010. 


\section{FUTURE WORK}

NGNP Engineering Process Heat Applications provided important new capability enhancements to INL and measurably advanced hydrogen production technology. The following items are vital to build upon these accomplishments and to prepare hydrogen production technologies for deployment with NGNP.

- Continue high temperature materials testing in MISTER at prototypic pressures and a variety of gas compositions and durations to demonstrate HTSE materials performance. Future testing should include cycling, loading, contamination effects, and coatings.

- Complete the assembly and startup of SPECTR to demonstrate HTSE stack testing under pressure.

- Continue diffusion bonding testing to select and qualify materials and joining methods for extreme high temperature and pressure components, including HTSE interconnects.

- Leverage the enormous potential for using atomistic/molecular and thermokinetic modeling to speed HTSE materials testing, selection, and qualification. The convergence of computational power, materials understanding based on physical exams, and intelligent software now provides significant advances in experimental designs.

- Continue CFD modeling to inform the optimum design of HTSE cells, stacks, and eventually modules and manifolds.

- The TPAC represents a major new capability to understand tritium management. This pivotal work must continue to ensure that industrial applications and hydrogen production can operate without tritium concerns.

- Update hydrogen production economic analyses as technology matures and assumption change. 